Supporting information

\title{
Substitution of $O$ with Single Au Atom as an Electron Acceptor in Al Oxide
}

\section{Clusters}

\author{
Fumitaka Mafuné*, Xinan Liu, Yufei Zhang and Satoshi Kudoh \\ Department of Basic Science, School of Arts and Sciences, The University of Tokyo, Komaba, \\ Meguro, Tokyo 153-8902, Japan \\ Email: mafune@cluster.c.u-tokyo.ac.jp
}




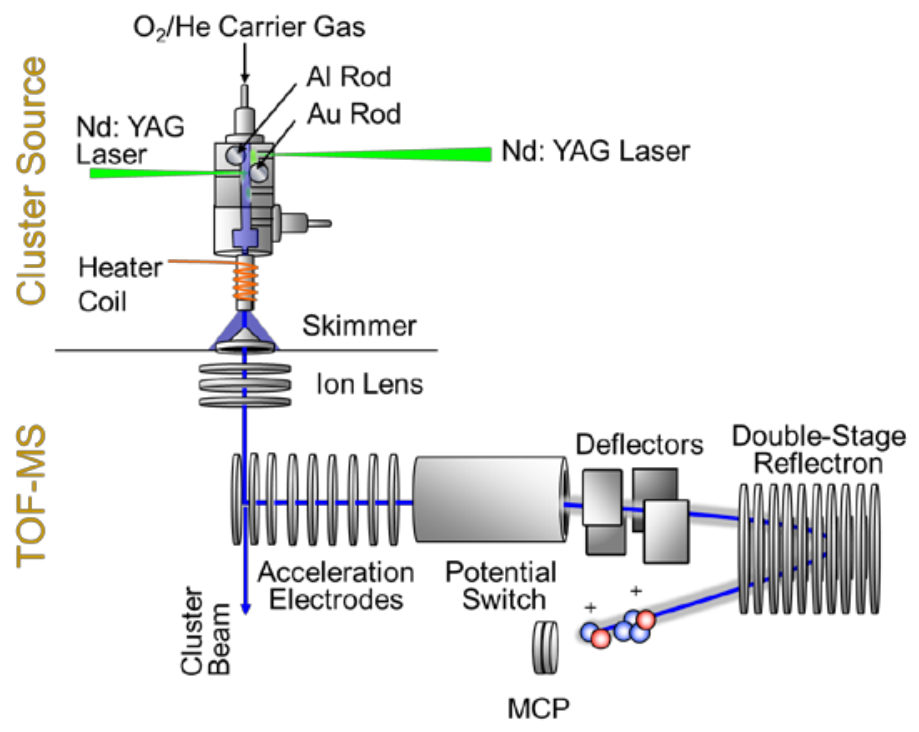

Figure S1 Experimental setup composed of a laser ablation source and time-of-flight mass spectrometer.

(a)

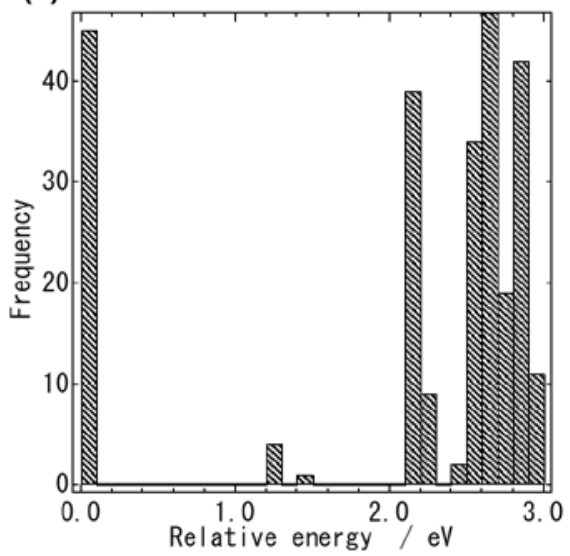

(b)

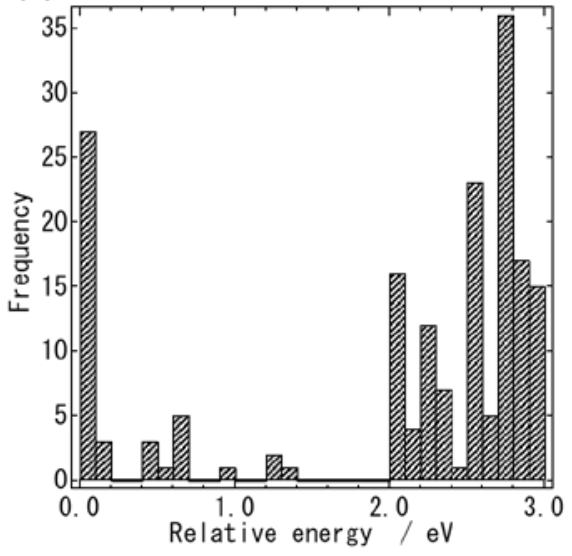

Figure S2 (a) Emergence distribution of isomers obtained from 1000 different randomly set geometries for $\mathrm{Al}_{4} \mathrm{O}_{5}{ }^{+}$in the primary screening using the 6-31G* basis set and LanL2DZ basis set for $\mathrm{Al}$ and $\mathrm{O}$ atoms and for $\mathrm{Au}$ atom, respectively, as a function of relative energy from the most stable isomer. The spin state of the stable isomers was doublet and the isomers with the higher spin states appeared above $2.6 \mathrm{eV}$. The most stable, second and third most stable isomers appeared 44 times, 4 times and 1 time in the primary screening, which were assigned to 045A, 045B and 045C 
after the calculations using larger basis sets, respectively.

(b) Emergence distribution of isomers for $\mathrm{Al}_{4} \mathrm{O}_{6}{ }^{+}$in the primary screening. The spin state of the stable isomers was doublet and the isomers with the higher spin states appeared above $2.5 \mathrm{eV}$. The most stable isomer appeared 27 times and the second isomer with a slightly higher energy than the most stable one appeared 3 times, both of which were converged to a unique structure and assigned to $046 \mathrm{~A}$ after the calculations using larger basis sets. $046 \mathrm{~B}$ and $046 \mathrm{C}$ originates from the third peak comprising two isomers which is $0.5 \mathrm{eV}$ higher than the most stable one.

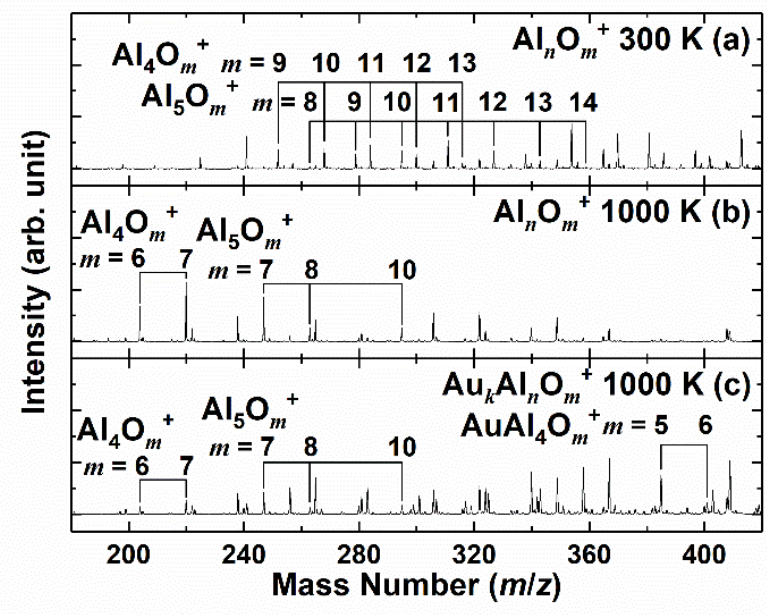

Figure S3 (a) Mass spectra of pristine $\mathrm{Al}$ oxide cluster ions formed at $300 \mathrm{~K}$ and (b) cluster ions formed after heating at $1000 \mathrm{~K}$ in the extension tube. (c) Mass spectrum of Au-Al oxide cluster ions formed after heating at $1000 \mathrm{~K}$. 


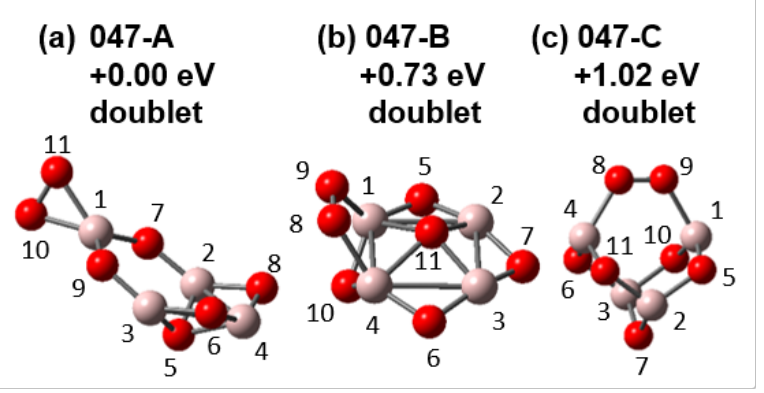

Figure S4 Stable structures of $\mathrm{Al}_{4} \mathrm{O}_{7}{ }^{+}$obtained by DFT calculations. Isomer 047-A is most stable and the difference in the formation energy is shown for each cluster.

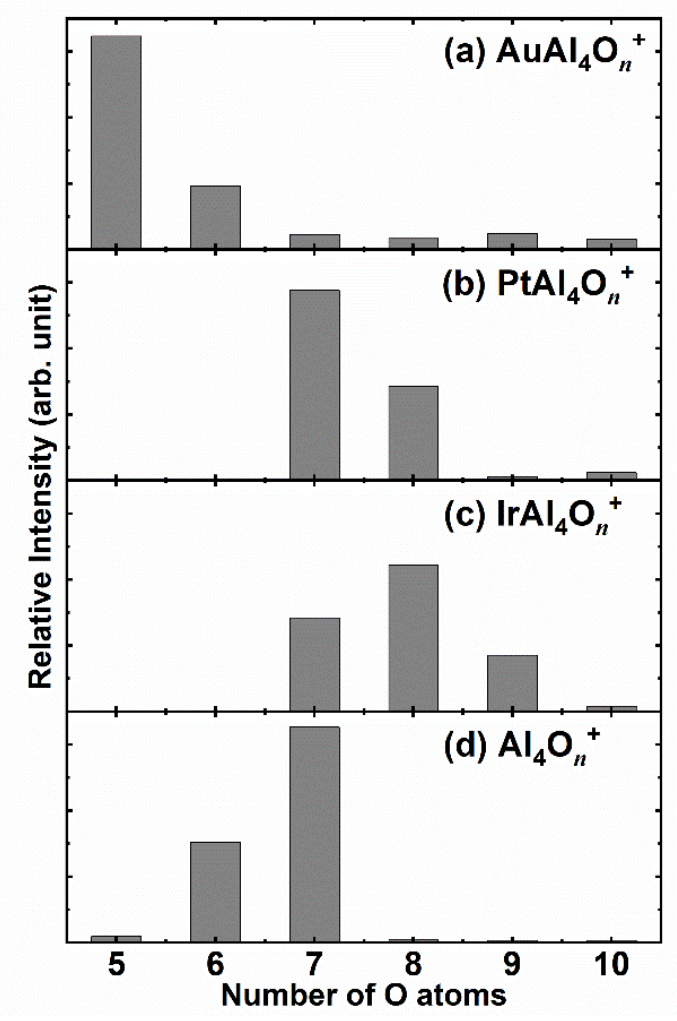

Figure S5 Relative intensities of core clusters, (a) $\mathrm{AuAl}_{4} \mathrm{O}_{n}{ }^{+}$, (b) $\mathrm{PtAl}_{4} \mathrm{O}_{n}{ }^{+}$, (c) $\mathrm{IrAl}_{4} \mathrm{O}_{n}{ }^{+}$and (d) $\mathrm{Al}_{4} \mathrm{O}_{n}{ }^{+}$with the number of $\mathrm{O}$ atoms, $n$, produced after passing the extension tube heated at $1000 \mathrm{~K}$. 


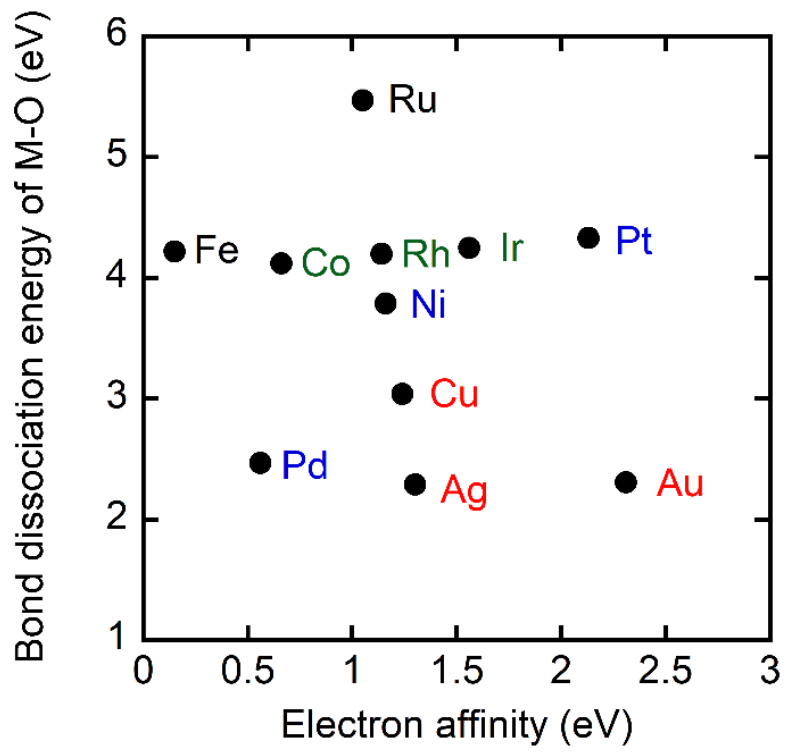

Figure S6 Scatter plot of the selected elements, M, for the electron affinity and for bond dissociation energy of the diatomic $\mathrm{M}-\mathrm{O}$ for $\mathrm{M}=\mathrm{Au}, \mathrm{Pt}, \mathrm{Ir}, \mathrm{Ag}, \mathrm{Cu}, \mathrm{Ni}, \mathrm{Rh}, \mathrm{Ru}, \mathrm{Co}, \mathrm{Pd}$ and $\mathrm{Fe}$. Group 8,9,10, and 11 elements are marked in black, green, blue and red, respectively. Gold is a unique element that has high electron affinity and low oxygen affinity.

Table S1 Bond dissociation energies of diatomic $\mathrm{M}-\mathrm{O}$ in eV cited from a literature and calculated by $\mathrm{DFT} \mathrm{M}=\mathrm{Au}, \mathrm{Pt}, \mathrm{Ir}, \mathrm{Ag}, \mathrm{Cu}, \mathrm{Ni}, \mathrm{Rh}, \mathrm{Ru}, \mathrm{Co}, \mathrm{Pd}$ and Fe.

\begin{tabular}{ccc}
\hline atom, M & $\begin{array}{c}\text { DFT } \\
\text { calculations }\end{array}$ & experiments \\
\hline $\mathrm{Au}$ & 1.82 & 2.31 \\
$\mathrm{Pt}$ & 3.58 & 4.33 \\
$\mathrm{Ir}$ & 4.26 & 4.25 \\
$\mathrm{Ag}$ & 1.86 & 2.29 \\
$\mathrm{Cu}$ & 2.63 & 3.04 \\
$\mathrm{Ni}$ & 3.56 & 3.79 \\
$\mathrm{Rh}$ & 3.78 & 4.20 \\
$\mathrm{Ru}$ & 4.50 & 5.47 \\
$\mathrm{Co}$ & 3.28 & 4.12 \\
$\mathrm{Pd}$ & 2.37 & 2.47 \\
$\mathrm{Fe}$ & 4.70 & 4.22 \\
\hline
\end{tabular}

